\title{
Contra la distinción: la libertad de las formas en la experiencia estética contemporánea
}

Against distinction: the freedom of the shapes in the contemporary esthetic experience

\author{
> Isabel Molinas \\ Universidad Nacional del Litoral, Argentina \\ isabelmolinas8@gmail.com
}

\begin{abstract}
In the field of Contemporary Esthetics is resumed the question of what is art and which are the readability conditions (reading). The questions relate to the displacement between representation and experimentation, beauty and esthetic experience, among others. In this context, we address the technology of poetry (Nancy (2012 [2013]) as technological exhibition that lets your experience the being of the object and become subjects. The corpus includes film and video (Kopystiansky 1996-97; Alys 2011 y Jaar 2013). The objective is to outline an analytical framework for thinking about the esthetic freedom of creation and the practical freedom of their recognition. (Wagner 2004).
\end{abstract}

Reywords: Art; Technology; Esthetics; Design; Freedom.

\section{Introduction}

De manera recurrente, en los últimos quince años, en el campo de las llamadas Estéticas Contemporáneas se ha retomado la pregunta sobre qué es el arte y cuáles son las condiciones de legibilidad del mismo (Seel 2000 [2010], Bourriaud (1998 [2006]), Rancière (2004 [2011]; 2011 [2012]), Nancy (2001 [2008]; 2012 [2013]) y Danto (2013). En todos los casos, se problematizan una vez más las nociones de mimesis y semiosis, se repliegan las fronteras artísticas, se introduce la noción de ecologías culturales, se toma partido por la experimentación y se trasciende el problema de la belleza y la distinción en el arte (Bourdieu 1979 [1998]) a partir del desplazamiento operado entre objetos de arte y objetos de pensamiento.

Dicha dilución de los límites entre disciplinas y el quiebre epistemológico enunciado en términos de 'giro estético', nos coloca frente a la necesidad de contar con nuevos instrumentos de orientación teórica y metodológica. Al respecto, Nancy (2012 [2013]: 312) propone atender al sentido mismo del término: ars-technétécnica y abordar la tecnología de la poesía ('poesía' en un sentido genérico y por antonomasia) como una exhibición tecnológica que en su materia y su técnica nos permiten experimentar el ser del objeto, el devenir sujetos y salir de dicha experiencia transformados. Porque "antes de ser un arte y antes de ser un objeto de estudio y de disfrute erudito, representa (...) un 'existenciario' en el sentido de Heidegger: una condición de posibilidad del existir en cuanto activación del ser; de nuestro ser actual”.

Para dar cuenta de este desplazamiento entre régimen de representación y régimen estético, seleccionamos tres propuestas -video-arte (Kopystiansky 1996-97), filme (Alÿs 2011) y registro audiovisual de una instalación (Jaar 2013)- a partir de las cuales esbozamos un marco analítico que prioriza la libertad estética de la creación y la libertad práctica de su reconocimiento (Wagner 2004), por encima de las ideas de belleza y de verdad en el mundo del arte. Los dispositivos tecnológicos elegidos, no sólo posibilitan dicha experiencia sino que potencian la comprensión intelectual de los alcances de las artes en el presente.

\section{Selección de obras}

Organizamos el corpus como un "laboratorio de imágenes", tal como lo concibe Aby Warburg (1926-1929 [2003]) en su Atlas Mnemosyne. Este 'primer panel' incluye tres piezas:

- "Incidents” de Igor y Svetlana Kopystiansky (1996-97). Video, sonido, instalación. 14:56 min. (Ediciones en MoMA, The Metropolitan Museum, Tade Modern y MNK Francfurt).

- "Reel-Unreel” de Francis Alÿs (Afganistán 2011). Filme, 19:29 minutos.

- "Venezia, Venezia" de Alfredo Jaar (2013). Instalación site-specific (documento visual y entrevista al artista). Pabellón de Chile. Bienal de Venecia.

El eje que las vertebra es el registro del paso del tiempo y la observación de aquello que funciona como residuo, el detalle inadvertido, los bordes y excrecencias, y al mismo tiempo, la denuncia y la conciencia de un tiempo artístico invertido en lo echado a perder.(a) En este contexto, la tecnología de la poesía permite unir 

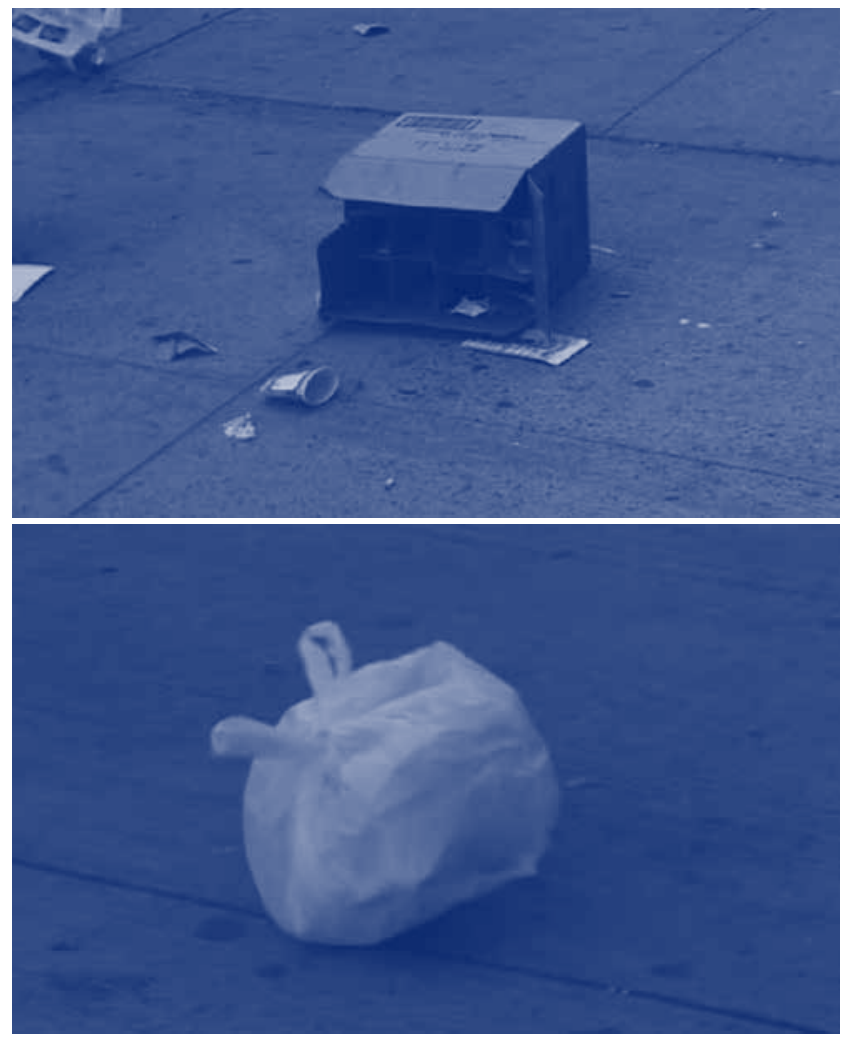

Figura 1 y Z: "Incidents" de Igor y Svetlana Kopystiansky (1996-97). Video, sonido, instalación. 14:56 min.

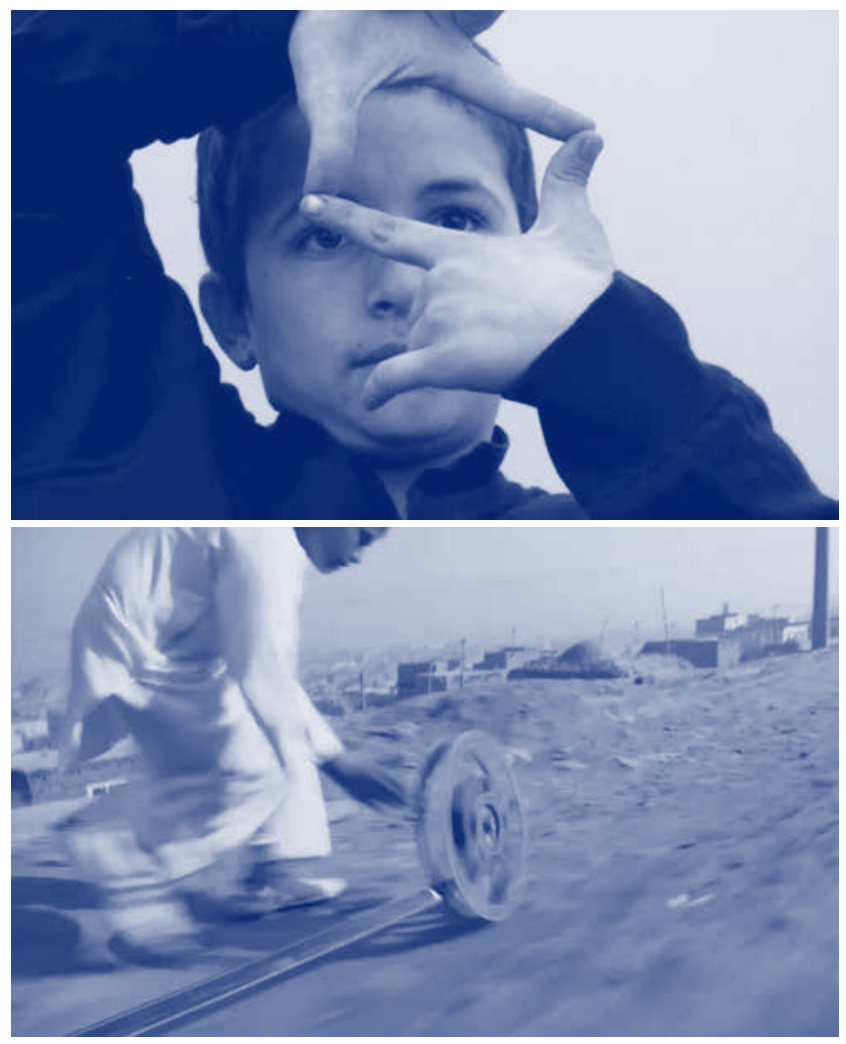

Figura $\exists$ y 4: "Reel-Unreel” de Francis Alÿs (Afganistán 2011). Filme, 19:29 min.
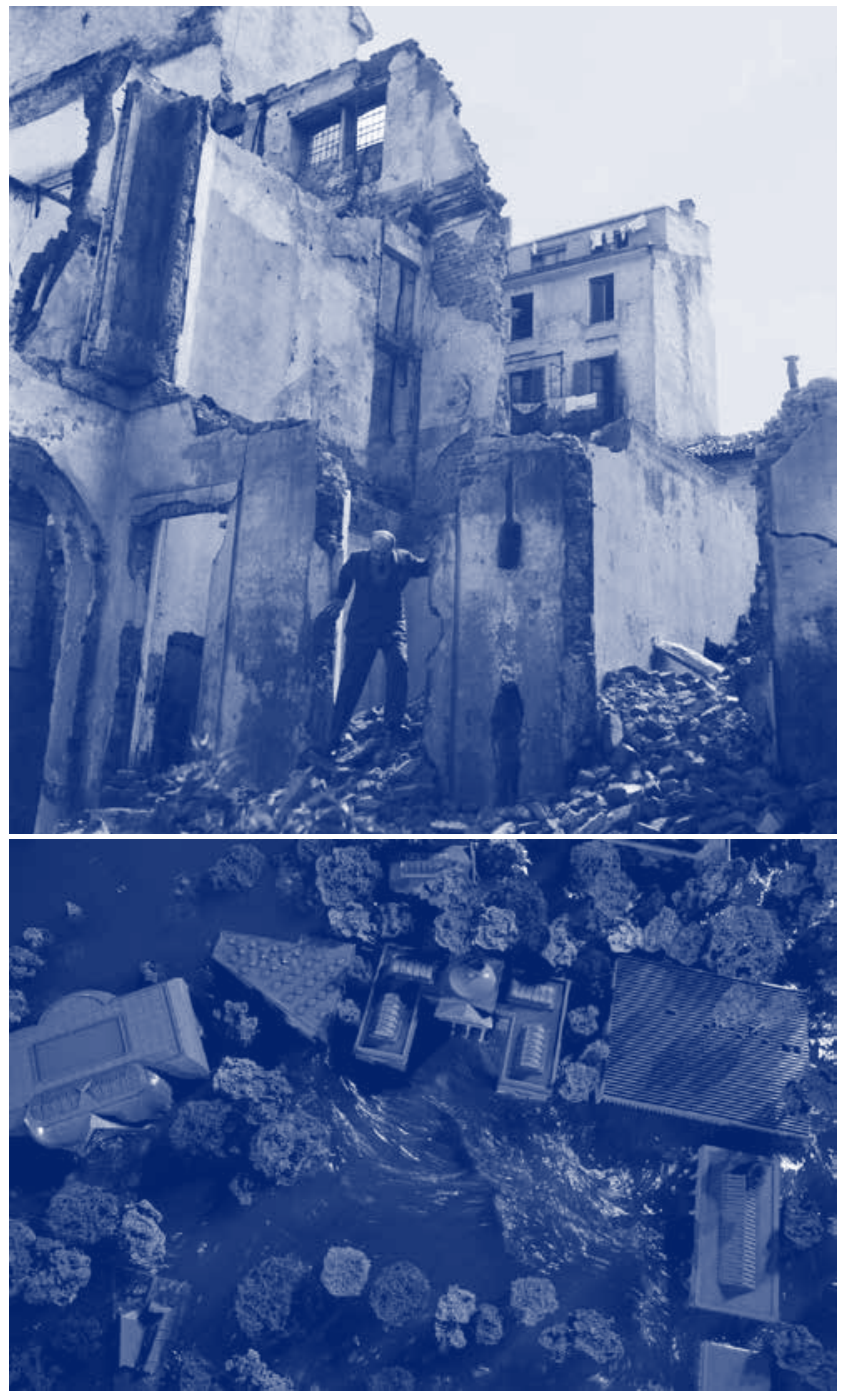

Figura 5 y 6: "Venezia, Venezia" de Alfredo Jaar (2013). Instalación sitespecific. Pabellón de Chile. Bienal de Venecia.

lo único con lo diverso y experimentar la mutua relación entre apariencia y experiencia estética.

Igor y Svetlana Kopystiansky (1996-97) hacen foco en la basura (una bolsa de residuo vacía, una caja de cartón rota, cubiertos de plástico, papeles) arrastrada por el viento en una ciudad que puede ser cualquiera. Tal como señala Seel (2004: 123): "Las imágenes no brindan ninguna información, sino que reproducen un acontecimiento único captándolo mediante el manejo de la cámara. La cámara se concentra en el movimiento de la bolsa por medio del zoom, a la vez que genera un movimiento propio. Esta concentración es el sentido estético del video. Tan solo se trata de captar algo en el proceso de su aparecer." (b)

El ojo de Francis Alÿs (2011) fija su mirada en la carrera de nińos que juegan con un aro/carrete de película en las calles de Kabul, Afganistán. A medida que el film avanza y nos adentramos en el ritmo y las costumbres de la ciudad, la cinta que se enreda y desenreda raya la película y hace explícita la prohibición de ver. En 
palabras de Speranza (2012: 18): "Son artistas y escritores del siglo XXI, contemporáneos, si por contemporáneo se entiende, como lo hace Giorgio Agamben (2010), artistas intempestivos, que están en su tiempo pero también pueden mirarlo con cierta distancia, percibir no sólo sus luces sino también su oscuridad, atender a los signos del presente pero también a lo arcaico”.

Finalmente, la instalación de Alfredo Jaar (2013) pareciera ser la crónica anunciada del hundimiento de un mundo y de una manera de concebir y gestionar el arte en el presente. En la entrada al Pabellón de Chile en la Bienal de Venecia, una fotografía del artista ítalo-argentino Lucio Fontana, en 1946, sobre las ruinas de su Estudio destruido por los bombardeos de la Segunda Guerra Mundial, es "una especie de manifiesto programático, invitación poética a reconsiderar el modelo expositivo de la Bienal" (Jaar 2013). A continuación, el espectador se encuentra con un puente "material y mental" que conduce a un espejo de agua, imagen de la laguna, de la que cada tres minutos emerge una réplica de los Giardini, con los veintiocho pabellones nacionales. Junto a la maqueta fantasmagórica del hundimiento, "la imagen de Lucio Fontana simboliza el poder del arte y de los intelectuales para traer el cambio al mundo" (Jaar 2013).

En las tres propuestas "la atención estética se adentra en la individualidad fenoménica de los objetos y su entorno y, por extensión, en el carácter irreductible de su presencialidad" (Seel 2004: 123).

\section{Libertad formal y experiencia estética}

Tal como seńalamos en la introducción de este trabajo, desde fines de los años 90 se registra una 'renovación de la estética' que se hace manifiesta en la creciente diferenciación de los hechos estéticos con respecto a las Artes y a los objetos de la Filosófica y de la Crítica. Al respecto, Jean Marie Schaeffer (2000 [2005]: 13) señala:

- la toma de conciencia sobre la imposibilidad de reducir la dimensión estética a la dimensión artística” (no es un atributo ligado exclusivamente al arte);

- la comprensión de la distancia entre la experiencia estética y los objetos de estudio de la Estética en tanto doctrina filosófica centrada en el juicio estético, en el estatuto ontológico de las obras del arte, en su legibilidad y en las relaciones entre arte y experiencia estética (no es un atributo necesariamente ligado a la filosofía); y

- la diferenciación entre juicio estético y valoración estética (no supone un juicio de razón y/o belleza).

Ahora bien, las más diversas situaciones y comportamientos podrían recibir esta calificación siempre y cuando presenten una estructura intencional común. El acento puesto en la experiencia hace del carácter relacional el rasgo necesario. La dimensión estética es siempre una propiedad relacional y no una propiedad del objeto. De allí que, junto a una estética del aparecer, cabría pensar en una estética relacional concebida como explicación sobre la forma poética de la experiencia antes que como una teoría del arte. En las piezas analizadas la libertad de las formas se hace visible en lo que el arte modeliza más que en lo que representa (Bourriaud 1998 [2006]: 17). Su eficacia radica en el modo en el que las obras se insertan en la trama social y renuevan la percepción de objetos, ciudades y universos simbólicos:
¿A qué llamamos forma? A una unidad coherente, una estructura (...) que presenta las caracteristicas de un mundo: la obra de arte no es la unica; es solo un subgrupo de la totalidad de las formas existentes. (...) Para crear un mundo, este encuentro debe ser duradero: los elementos que lo constituyen deben unirse en una forma, es decir que debe haber posesión de un elemento por otro. La forma puede definirse como un encuentro duradero. (1998 [2006]: 19)

Para explicar la 'pregnancia' de ese encuentro duradero, Bourriaud recurre a la definición que Deleuze y Guattari (1991 [2002]: 179-218) proponen de la obra de arte: "un bloque de sensaciones, es decir un compuesto de preceptos y afectos":

Los preceptos ya no son percepciones, son independientes de un estado de quienes los experimentan; los afectos ya no son sentimientos o afecciones, desbordan la fuerza de aquellos que pasan por ellos. (...) La obra de arte es un ser de sensación, y nada más: existe en sí. (...)

Se pinta, se esculpe, se compone, se escribe con sensaciones. Se pintan, se esculpen, se componen, se escriben sensaciones. (...) Por este motivo quien sólo es pintor también es algo más que pintor, porque "hace que surja ante nosotros, sobresaliendo del lienzo fijo", no la similitud, sino la sensación pura "de la flor torturada, del paisaje lacerado por el sable, arado y prensado", devolviendo "el agua de la pintura a la naturaleza. (c)

Ahora bien, ¿en qué consiste ese trabajo de 'saturar cada átomo'(d), a la vez que se despoja al discurso de lo que puede resultar superfluo o poco relevante? Deleuze y Guattari recurren a la noción de estilo para profundizar en lo que ya enunciamos en términos de una teoría de la forma poética de la experiencia:

El escritor (el creador) emplea palabras, pero creando una sintaxis que las hace entrar en la sensación, o que hace tartamudear a la lengua corriente, o estremecerse, o gritar, o hasta cantar: es el estilo, el "tono", el lenguaje de las sensaciones, o la lengua extranjera en la lengua, la que reclama un pueblo futuro. (...) El escritor retuerce el lenguaje, lo hace vibrar, lo abraza, lo hiende, para arrancar el precepto de las percepciones, el afecto de las afecciones, la sensación de la opinión, con vistas, eso esperamos, a ese pueblo que todavía falta. (Deleuze y Guattari (1991 [2002]: 193).

Tal como señala Wagner (2004: 169-171) en su relectura de la Crítica del Juicio de Kant, la libertad de la imaginación estética se manifiesta en el libre juego entre imaginación y entendimiento:

La experiencia estética demanda otro acceso al mundo sensible. Este acceso se revela en la densidad e intensidad perceptivas de una experiencia estética individual, asi como en las connotaciones y emociones vinculadas con ella. La 
libertad estética reside exactamente en el acto de vincular la densa intuición sensible con la discursividad más abstracta.

(...) La idea estética es un producto de la imaginación libre, de la imaginación como "impulso poético". Ella "condensa", "constituye analogias" y se haya en situación de reorganizary enriquecer la experiencia "merced a la creación de otra naturaleza, a partir del material que le brinda la naturaleza real".

(...) Semejantes actos creativos en el trato con las formas organizativas intuitivas y conceptuales presuponen un tipo especial de libertad: la libertad de la imaginación estética.

En términos de conocimiento, el principal aporte de esta lectura consiste en la posibilidad de suspender a partir de la libertad estética la propia conceptualización y la perspectiva del discernimiento, al admitir otras categorizaciones y juicios, e incluso otras interpretaciones sobre 'lo real'. Asimismo, la libertad estética nos desobliga frente a la libertad práctica de un único punto de vista. (Wagner 2004: 173).

\section{Notas}

a. El trabajo en lo echado a perder es la metáfora del decimoctavo hexagrama del I Ching. En dicha imagen del Libro de las mutaciones (editado por Wilhelm, Sudamericana 1975) primero hay que quitar la maleza, separar las ramas y preparar la tierra para dejar atrás las ataduras epistémicas.

b. Seel centra su análisis en una de las secuencias de American Beauty, de Sam Mendes (Estados Unidos, 1999), y advierte que "el vuelo de las bolsas plásticas parece ser un topos del videoarte”. Al respecto, remite al trabajo de Kopystiansky y a la obra del video-artista suizo Eric Hattan (Air, 1998 y Blowing in the wind, 1999).

c. Deleuze y Guattari retoman el ensayo de Artaud (1947) Van Gogh, el suicida de la sociedad, Madrid: Fundamentos, 1983, pp. 74-82.

d. Aquí los autores retoman el Diario de una escritora de V. Woolf (1953).

\section{Referencias}

Agamben, G. (2010) “¿Qué es lo contemporáneo?” Instituto Universitario de Arquitectura de Venecia. Disponible en: http:// www.ddooss.org/articulos/textos/Giorgio_Agamben.htm

Bourdieu, P. (1979) La distinción. Criterio y bases sociales del gusto. Madrid: Taurus, 1998.

Bourriaud, N. (1998) Estética relacional. Buenos Aires: Adriana Hidalgo, 2006.
Bourriaud, N. (2009) Radicante. Buenos Aires: Adriana Hidalgo, 2012.

Danto, A. (2013) Qué es el arte. Buenos Aires: Paidós.

Deleuze, G. y Guattari, F. (1991) ¿Qué es la filosofía? Madrid: Editora Nacional, 2002.

Dewey, J. (1934) El Arte como experiencia. Barcelona: Paidós, 2008. Eisner, E. (1990) El ojo ilustrado. Barcelona: Paidós, 1998.

Heidegger, M. (1952) Arte y poesía. México: FCE, 1988.

Jaar, A. (2013) "Alfredo Jaar, Venezia, Venecia". Entrevista de Loredana Mascheroni. En Domus, junio 2013. http://www.domusweb.it/es/arte/2013/06/24/alfredo_jaar_venicevenice.html

Kant, I. (1790) Crítica del juicio. Madrid: Espasa, 2006.

Laddaga, R. (2010) Estética de laboratorio. Buenos Aires: Adriana Hidalgo.

Mancuso, H. (1999) Metodología de la investigación en Ciencias Sociales. Lineamientos teóricos y prácticos de semioepistemología. Buenos Aires: Paidós.

Nancy, J. L. (2001) Las Musas. Buenos Aires: Amorrortu, 2008.

Nancy. J. L. (2012) La partición de las artes. Valencia: Pre-Textos/ Univ. Politécnica de Valencia.

Rancière, J. (2004) El malestar de la estética. Buenos Aires: Capital intelectual, 2011.

Rancière, Jacques (2011) Las distancias del cine. Buenos Aires: Manantial, 2012.

Schaeffer, Jean Marie (2000) Adiós a la estética. Madrid: Machado Libros, 2005.

Seel, Martin (2000) Estética del aparecer. Buenos Aires: Katz, 2010.

Seel, Martin (2007) "Un paso al interior de la Estética”, en Revista Estudios Filosóficos No 36, pp. 117-131, Colombia: Universidad de Antioquia.

Speranza, G. (2012) Atlas portátil de América latina. Arte y ficciones errantes. Buenos Aires: Anagrama.

Wagner, Astrid (2004) "Libertad estética y libertad práctica. La crítica del discernimiento y su incidencia en el concepto kantiano de "libertad moral". En ISEGORÍA No 30, Madrid, pps. 147-162.

Warburg, Aby (1926/1929) "Conferencia sobre Rembrant", "Conferencia en la Hertziana” y "Conferencia en la fiesta de los doctores”. En Warburg (2003) Atlas Mnemosyne. Madrid: Akal, 2010.

\section{Fotografias}

http://www.metmuseum.org/metmedia/video/collections/ph/incidents

http://www.francisalys.com/public/reel-unreel.html

http://www.domusweb.it/es/arte/2013/06/24/alfredo_jaar_venicevenice.html 